\title{
Assessment of Validity of the National Public Health Performance Standards: The Local Public Health Performance Assessment Instrument
}

Joyce Beaulieu, PhD, MPH

F. Douglas Scutchfield, MD

\section{SYNOPSIS}

The National Public Health Performance Standards Program (NPHPSP) has developed performance standards measurement instruments, based on the 10 "Essential Services of Public Health" that are being tested in several states. This article is a report on the face and content validity of the instrument designed for local public health systems.

Judgments about the face validity of the standards were obtained in a survey of local public health systems that had used the instrument in a test state. The validity of each standard was addressed along the following dimensions: the importance of the standard as a measure of the Essential Service; its completeness as a measure; and its reasonableness for achievement. All standards for each Essential Service were then judged in terms of their completeness in measuring performance of that service.

Respondents judged the standards to be highly valid measures of local public health system performance. Some respondents had reservations about whether standards related to "enforcing laws and regulations" were achievable. Holding local public health systems accountable for the activities of other agencies was a factor mentioned in conjunction with those standards.

The NPHPSP standards have face and content validity for measuring local public health system performance. Further testing of their validity and reliability is continuing.

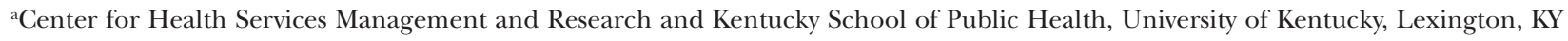
Address correspondence to: Joyce Beaulieu, PhD, MPH, UK Center for Health Services Management and Research, 109 CAHP Bldg., 121 Washington Ave., Lexington, KY 40536; tel. 859-257-6430; fax 859-257-2454; e-mail: <jebeau01@pop.uky.edu>.

()ㅜㄹ Association of Schools of Public Health 
Throughout the health care system, improvements in the quality of services and their attendant health outcomes have spurred system reform over the last decade. Combined with policies to improve the accountability of government agencies, public health departments have been the focus of several performance improvement efforts. ${ }^{1,2}$ Starting with the 1988 Institute of Medicine report, The Future of Public Health, the need for better measures of public health performance began to receive increased attention. ${ }^{3-5}$ In the early $1990 \mathrm{~s}$, researchers developed and tested methods of measuring public health department performance. ${ }^{6,7}$ Characteristics of local health departments and their practices began to be described using these measurement instruments. ${ }^{8-12}$

While performance measures have been applied to local public health departments, little research to date has addressed measures of the public health system. ${ }^{14}$ The system is the broad array of public and private health and health-related agencies and organizations that contribute to, and directly provide, the services and activities that fall within the public health functions of assessment, policy development, and assurance. ${ }^{15}$ Development and testing of measures of public health system performance is one of the goals of a program involving several national public health organizations.

\section{THE NATIONAL PUBLIC HEALTH PERFORMANCE STANDARDS PROGRAM}

The Centers for Disease Control and Prevention (CDC) Public Health Program Practice Office (PHPPO) has convened national partners in the National Public Health Performance Standards Program (NPHPSP) "to improve the practice of public health by providing leadership in research, development, and implementation of science-based performance standards." ${ }^{16}$ The objectives of the NPHPSP are to: (a) develop performance standards for public health practice as defined by the 10 "Essential Services of Public Health,"18 (b) collect and analyze performance data, and $(c)$ improve system-wide performance. ${ }^{16}$ The National Association of City and County Health Officials, the Association of State and Territorial Health Officers, the National Association of Local Boards of Health, the American Public Health Association, and the Public Health Foundation have worked with the CDC to design comprehensive performance measurement tools for the assessment of public health practice. Tools are being developed and evaluated for local public health systems, state public health systems, and state or local public health governing boards. The standards con- tained in each of these measurement instruments are keyed to the Essential Services of Public Health, ${ }^{18}$ subsumed under the assessment, policy development, and assurance functions.

The methods for their development and the theoretic underpinning of the proposed performance standards have been described elsewhere. ${ }^{14,15}$ The model standards, developed by the CDC and national public health partners, reflect "guidance from source documents that describe performance standards in fields of public health related to various Essential Services of Public Health. The model standards represent expert opinion concerning those actions and capacities that are necessary for a local public health system to be a high performing system." ${ }^{\prime 7}$

\section{LOCAL PUBLIC HEALTH PERFORMANCE ASSESSMENT INSTRUMENT}

The local public health system measurement instrument is a self-assessment rating system. Each Essential Service is linked to one or more indicators. Each indicator is described and explicated by a model standard. The instrument elicits responses about the activities performed by the local public health system in relation to the model standards.

The tool explicitly incorporates the idea of partnerships among components of local public health systems in their performance of the activities described by the model standards. Partners of the local public health department or other local government entity responsible for public health are meant to provide input on their role(s) in public health performance, along with the local government entity. Respondents are asked to describe indicators as "met," "partially met," or "not met." The current version of the local public health performance measurement instrument can be found on the NPHPSP website. ${ }^{17}$

The instrument has had several field tests, starting in Texas in 1999, where a sample of local health departments completed the tool on-line. From that experience the instrument was further refined. The revised instrument was further tested in September 1999 in all 67 county health departments in Florida using a paper and pencil format.

We report here on face and content validity of the indicators and model standards, using the Florida data. Criterion validity is also being assessed and will be reported in a later publication. Validity is the extent to which a measure captures the intended phenomenon. Face validity is expert judgment about whether a measurement is valid "on its face," or as it appears. Content validity is the extent to which a set of items 
measures all the facets of the phenomenon. ${ }^{19}$ Criterion validity is the test of the measure against a "gold standard," in this case, other measures of the local public health system's performance.

The measurement of the content validity of the local public health performance assessment instrument is concerned with the question: Are we measuring public health system performance? Under this overarching question, a number of facets of public health performance are subsumed:

- How well are we measuring what a public health system does?

- Do the specific indicators adequately measure performance in each Essential Service?

- How completely are we measuring the entire content of public health performance?

- What indicator measures are included that should be excluded? (The indicators should not be redundant or irrelevant.)

- What indicator measures are left out that should be included? (The indicators should not omit dimensions of the model standard that are essential to public health system performance.)

- Are indicator measures valid for all public health systems (a measure of external validity, also called generalizability)?

Research on public health department performance has linked effectiveness to having full-time executive leadership, larger expenditures, more total staff, Medicaid clients, and private insurance revenue. ${ }^{11}$ We chose one key measure, health jurisdiction size, as a proxy for these more specific health department characteristics.

Our operationalization of validity-the extent to which the standards and specific indicators measure good public health system practice-was assessed by the staff of Florida local public health departments. In some (though not all) Florida counties, partners were involved in the process of responding to the assessment instrument. For instance, partners were involved in more rural counties that rely on community agencies to assure that essential public health services are covered (such as rural counties that have very close ties with school districts to provide vaccinations). Local public health partners were not involved in the test in most counties. We addressed validity, therefore, from the viewpoint of the staff of the local health department.

The questions and format for eliciting validity judgments were developed by the present authors, work- ing with the PHPPO, the NPHPSP, and executive staff of the Florida Department of Health. The most efficient method of administering the questions was deemed to be electronic mailing to all Florida local public health department directors, asking them to reply to the state Department of Health. Replies were forwarded to the University of Kentucky researchers.

The survey sought answers to three aspects of the validity of each indicator and accompanying model standard:

- Does the model standard contain the key elements of good public health practice?

- Does the model standard completely describe the indicator?

- Is it reasonable to expect local public health systems to achieve the model standard?

The survey also assessed the validity of the indicators representing each Essential Service by asking:

- Do the indicators taken together completely describe all the public health activities that should be measured within that Essential Service?

The validity questions were in the form of statements against which the respondent judged their degree of agreement or disagreement on a 5-point Likerttype scale, with $1=$ strongly agree, $5=$ strongly disagree, and $3=$ neither agree nor disagree. Mean scores were calculated on each question for each indicator. In addition to the univariate statistics, a bivariate analysis was performed using ANOVA to determine mean differences in scores between small (population $<50,000$ ), medium (population 50,000-250,000) and large (population $>250,000)$ health department jurisdictions.

\section{FINDINGS}

We received useable responses from 50 of the 67 local health departments, for a response rate of $75 \%$. We examined the scores for each of the 10 Essential Services of Public Health and each of the 31 indicators and accompanying model standards. In judging the mean score for each question, we used a break-point score of 2.2 as indicating agreement with the validity of the model standard. We chose 2.2 as a reasonable threshold of agreement because 2 denotes "agree" on our Likert scale and 3 denotes "neither agree or disagree;" 2.2 was considered a more conservative mean threshold to denote agreement. The great majority of the respondents were in agreement with the validity statements, with means ranging from 1.0 to 2.2. Mean scores are shown in the Table. 


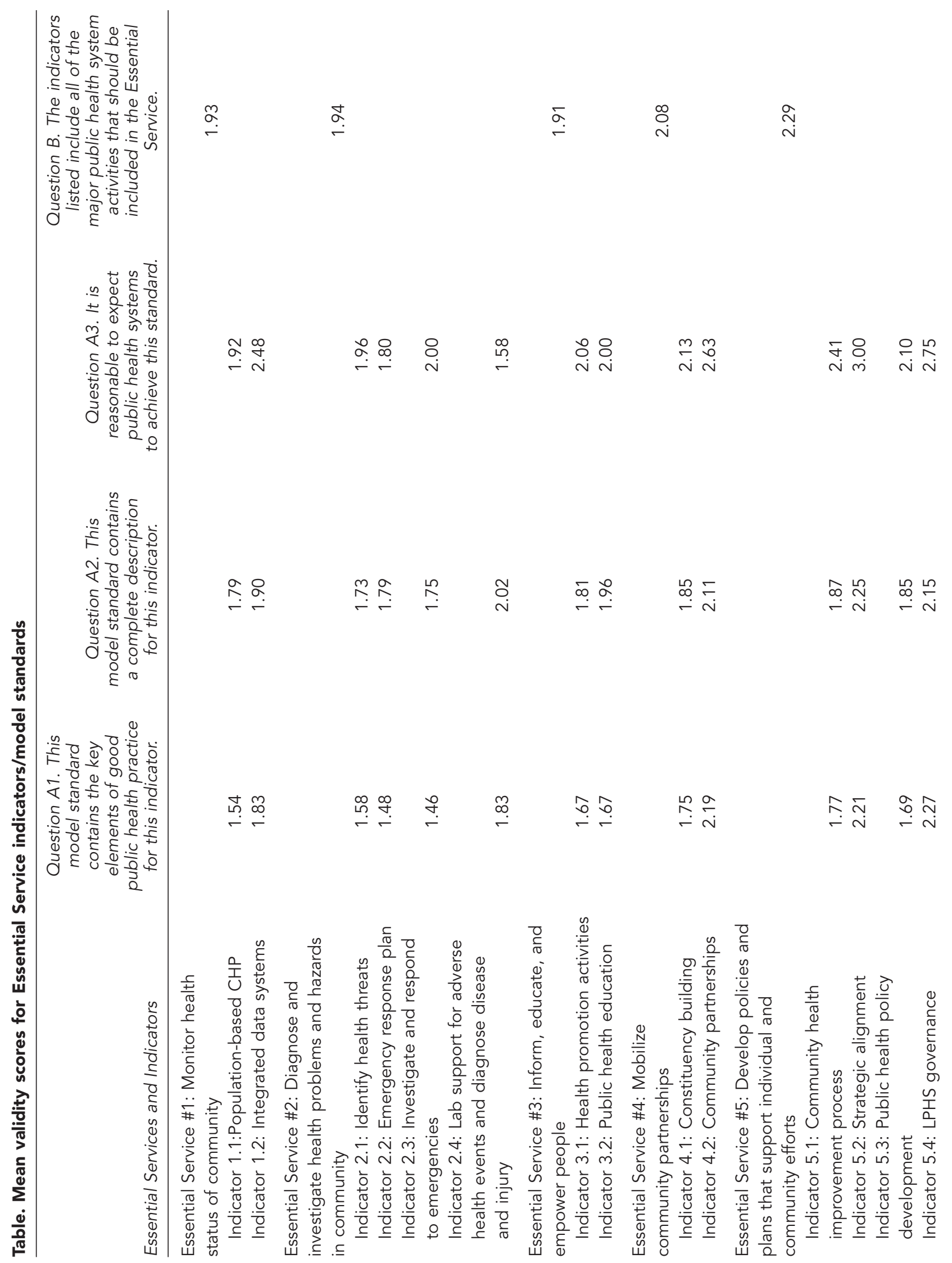

Public Health Reports / January-February 2002 / Volume 117 


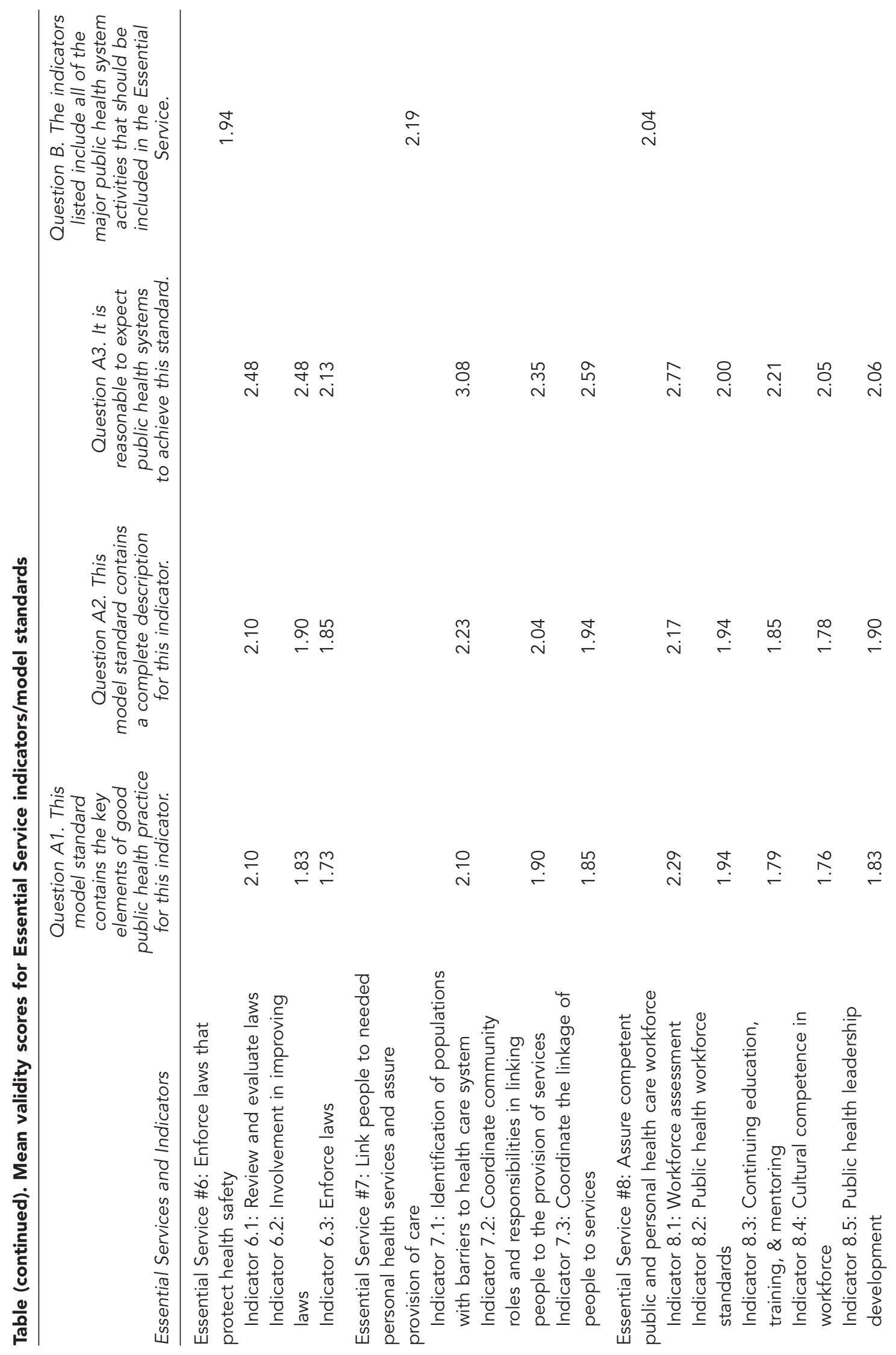

Public Health Reports / January-February 2002 / Volume 117 


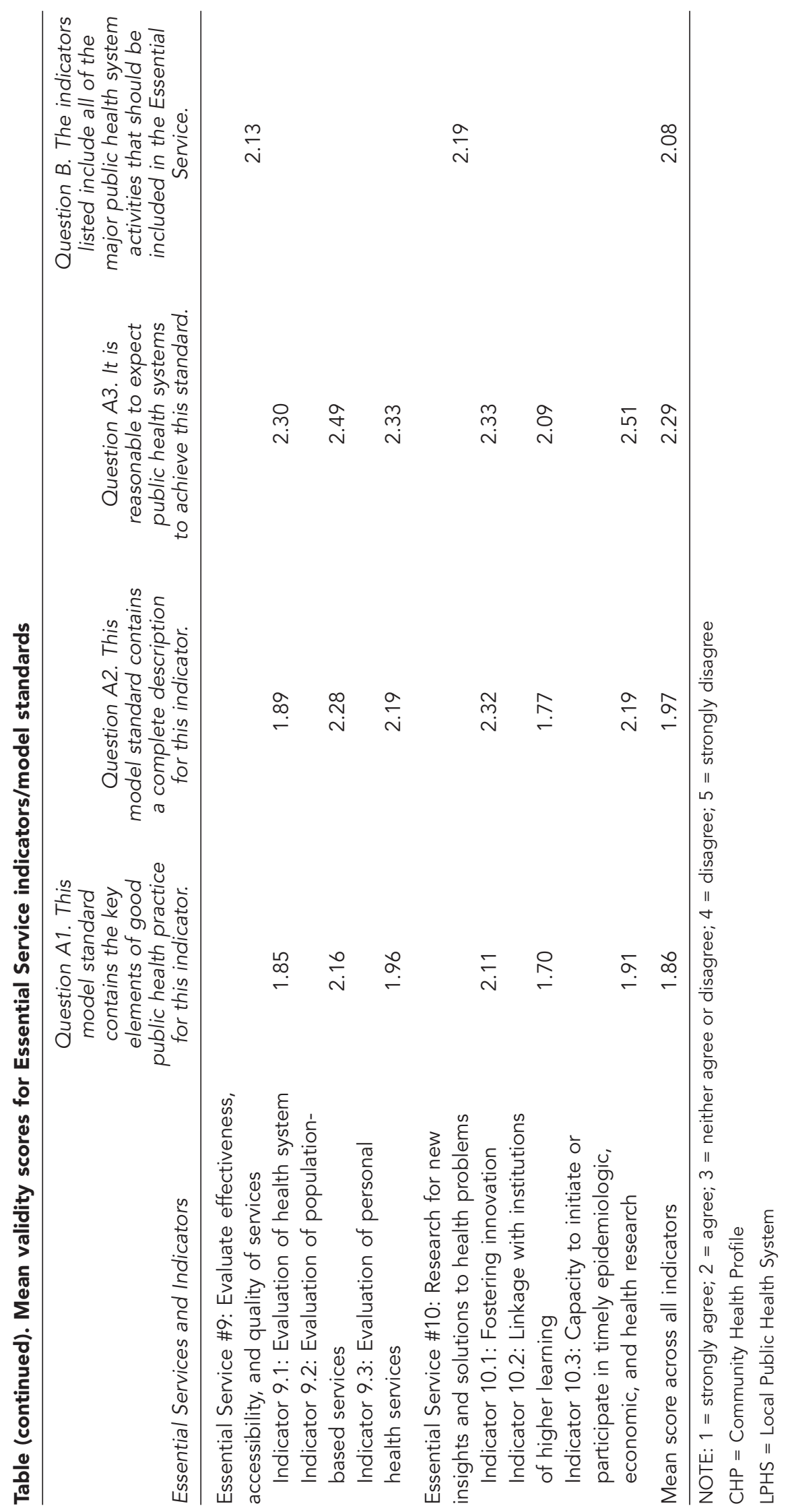

Public Health Reports / January-February 2002 / Volume 117 
Key elements of good public health practice Summary statistics show general agreement that each model standard "contains the key elements of good public health practice." In only three of the 31 indicators was the mean score higher than 2.2, at 2.3 ("Strategic Alignment," "Local Governance," and "Workforce Assessment").

\section{Completeness of the model standard}

The completeness of the model standard in describing the indicator (that is, "the model standard contains a complete description of [indicator]") was likewise readily accepted by our respondents, with 27 of 31 scores higher than 2.2. Slight disagreement (2.3) was noted for "Strategic Alignment", "Identification of Populations with Barriers ... .," "Evaluation of Population Based Services," and "Fostering Innovation."

\section{Achievability}

The least agreement on the validity of the instrument was obtained in answer to whether it was "reasonable to expect public health systems to achieve this standard." For this question, 14 of the 31 model standards, or $45 \%$, exceeded our 2.2 cut point. The essential services for which all standards were not seen as achievable included, for example, \#7, addressing Linkage of Services and Populations, and \#9, addressing Evaluation and Quality Assurance. For two essential services, \#2 ("Diagnosis and Investigation of Health Problems") and \#3 ("Inform, Educate and Empower People") among others, all standards were seen as achievable.

\section{Completeness of indicators for the Essential Service}

For the question about whether the standards included all of the performance measures for that Essential Service, agreement was seen for nine of the 10 essential services; only \#5 ("Develop Policies and Plans . ..") was rated higher than 2.2. Respondents made no specific comments on how the indicators for this Essential Service could be made more complete.

\section{Validity within essential pubic health services}

We also examined scores within each Essential Service to determine patterns across each validity question. Validity was agreed upon across the dimensions of completeness, adequacy, and achievability within each of the first four essential services, with only an occasional mean extending beyond our 2.2 cut point. For \#1 ("Monitor Health Status"), the mean score for one of six indicators was $\geq 2.2$. For \#2 ("Diagnose and Investigate Health Problems"), mean scores for zero of 12 indicators, and \#3 ("Inform, Educate and Empower People," zero of six indicators were $>2.2$. For
\#4 ("Mobilize Community Partnerships"), one of six indicators was $>2.2$.

Lack of agreement on validity of standards for \#5, "Develop Policies and Plans that Support Individual and Community Health Efforts," was evident, as mean scores on six of the 13 indicators exceeded 2.2. Within that essential service, respondents had specific validity difficulties with two indicators, "Strategic Alignment," for which mean scores on all of the validity questions exceeded 2.2 and "Local Public Health System Governance," for which mean scores on two of the three questions exceeded 2.2.

For \# 6, "Enforce Laws and Regulations that Protect the Health and Ensure Safety," there was disagreement about achievability; mean scores on two of the three indicators were $>2.2$.

For \#7, "Link People to Needed Health Services," there were reservations about the achievability of all indicators. For one indicator related to this essential service, respondents questioned the completeness of the model standard.

For \#8, "Assure a Competent Public and Personal Health Care Workforce," low validity scores were found for three of 15 indicators in "key elements" of workforce assessment, achievability of workforce assessment, and achievability of continuing education.

For \#9, "Evaluate Effectiveness, Accessibility, and Quality of Personal and Population-based Health Services," respondents questioned the achievability of all three of the indicators.

For \#10, "Research for New Insights and Innovative Solutions to Health Problems," two mean scores on achievability exceeded 2.2 for two of the three indicators, "Fostering Innovation" and "Capacity to Initiate Research;" respondents questioned the validity of "Fostering Innovation" with regard to completeness of the model standard.

\section{Size of health department}

Our examination of the validity of the standards by size of health department jurisdiction revealed no major differences. For only four of the 93 potential validity responses were there differences in the means between small $(<50,000)$ or medium-sized $(50,000-$ $250,000)$ jurisdictions.

\section{DISCUSSION}

This examination of specific aspects of the validity of the local public health performance measurement instrument resulted in a finding that it is a valid instrument. In very few cases was there any major disagreement among our respondents on whether the model 
standard contained the elements of good public health practice. Likewise there was comfort that the model standard completely and adequately described the indicators included on the instrument. In addition, the indicators for each of the essential services were seen as inclusive; that is, they included all that are necessary for the essential service. One exception to this finding was the validity of many aspects of \#5, "Develop Policies and Plans."

The more difficult issue for our respondents was the issue of whether local public health systems could be expected to achieve the standard. The CDC and its partners created the instrument to assess the performance of the "public health system." This notion includes not only the local public health department, but also other partners in the community that, together, constitute a local public health system. While the instrument was developed to assess a system, the instrument did not receive a full test using "system partners," which may have contributed to disagreement that local public health departments could be held accountable for local public health system performance.

A local public health department may function to assure that some Essential Services are performed, but may not necessarily perform them directly. In a subsequent site visit to several of these local health departments conducted as a part of the criterion validity testing, we confirmed that the issue of the performance of the "system" versus the "health department" confused some respondents in their use of the instrument. In discussing these issues, health department directors stated that in many cases the public health department cannot be held accountable for what others do or do not accomplish. This issue continues to be a source of discussion as the instrument and the instructions are refined. Health department directors also commented on the need for adequate funding to meet all of the model standards.

It is also apparent that achievability is an issue with regard to specific essential services. A review of our data suggests real concern surrounding the performance of "medical care" as opposed to traditional public health activities. The two essential services concerned with sickness care represented specific achievability problems: \#7, "Linking People to Needed Personal Health Services," and \#9, "Evaluation of Effectiveness, Access and Quality of Personal and Population Based Services." Given the continuing substantial debate over the role of health departments as the caregiver of last resort, it is not surprising to find this disagreement.

Likewise it is not surprising to find disagreement about the achievability of workforce assessment, essen- tial service \#8. Health departments were unsure of the workforce practices of personal health agencies, such as hospitals, in their jurisdictions. Site visits confirmed this uneasiness about knowing the personnel activities of private health care providers.

Similar disagreement was found for research responsibilities, Essential Service \#10. In many jurisdictions, governmental public health agencies deliver and fund services at the local or state level, but do not value a state or local public health department's role in research and innovation. Research is perceived to be the responsibility of universities rather than health departments. Better understanding of the role and incentives for public health departments in partnering with research institutions is needed to assure more public health innovation.

More surprising is the disagreement on achievability of model standards for enforcing laws and regulations. The police power of the state relating to assuring the public's health has long been delegated to local public health departments. In fact, historically, they were formed to enforce quarantines. Anecdotal evidence from site visits documented a split in local responsibility over some aspects of public health between environmental, business regulation, and public health agencies. This contributed to public health departments' difficulties in assessing their own performance, and may in turn be a factor in judgments about the validity of that essential service. Given the existence of different regulatory authority and jurisdictions among state and local agencies in other states, a better understanding of the validity of measures of regulatory authority can potentially be gained as the instrument is tested in other states.

The finding that agreement about validity did not vary substantially across sizes of public health jurisdictions provides further confirmation of our findings. As noted above, Turnock and Handler have related the effectiveness of local health departments to a number of organizational variables. ${ }^{1}$ We chose size as a proxy for those variables, but it may not be a useful proxy. Nevertheless, the lack of variability across health departments certainly bolsters the generalizability (external validity) of the standards and the measurement instrument.

Work on the validity and reliability of the public health performance standards has just begun. Modifications were made in the instrument and how it was administered following the Florida experience, although the testing thus far has not included community partners to a great extent.

The potential of the public health performance assessment instrument to improve the performance of 
local public health systems remains an important goal worth pursuing, and the assurance of its validity is key to the success of the NPHPSP.

The authors thank CDC staff members Paul K. Halverson, DrPH, MHSA, Director, Division of Public Health Systems Development and Research, Public Health Practice Program Office, and Director, National Public Health Performance Standards Program; Pomeroy Sinnock, PhD; and Rosemary Bakes-Martin, MS; for their assistance in the development and interpretation of the survey.

The evaluation of the public health performance assessment instruments is funded by a cooperative agreement between the University of Kentucky; the Association of Teachers of Preventive Medicine; and the Centers for Disease Control and Prevention (CDC).

\section{REFERENCES}

1. Turnock BJ, Handler AS. From measuring to improving public health practice. Annu Rev Public Health. 1997;18:261-82.

2. Baker EL, Melton RJ, Stange PV, Fields ML, Koplan JP, Guerra FA, Satcher D. Health reform and the health of the public. JAMA 1994;272:1276-82.

3. Institute of Medicine. The future of public health. Washington: Institute of Medicine; 1988.

4. Scutchfield FD, Beversdorf CA, Hiftabiddle S, Violante T. A survey of state health department compliance with the recommendations of the Institute of Medicine report, The Future of Public Health. J Public Health Policy 1997; 18(1): 13-29.

5. Roper WL, Baker EL, Dyal WW, Nicola RM. Strengthening the public health system. Public Health Rep 1992;107:609-15.

6. Miller CA, Moore KS, Richards TB, Monk JD. A proposed method for assessing the performance of local public health functions and practices. Am J Public Health 1994;84:1743-9.

7. Miller CA, Moore KD, Richards TB, McKaig C. A screening survey to assess local public health performance Public Health Rep 1994;109:659-64.

8. Turnock BJ, Handler A, Hall W, Potsic S, Nalluri, Vaughn EH. Local health department effectiveness in addressing core functions of public health. Public Health Rep 1994;109:653-8.
9. Turnock BJ, Handler A, Dyal WW, Christensen G, Vaughn EH, Rowitz L, et al. Implementing and assessing organizational practices in local health departments. Public Health Rep 1994;109:478-84.

10. Turnock BJ, Handler AS, Miller CA. Core functionrelated local public health practice effectiveness. J Public Health Manage Pract 1998;4(5):26-32.

11. Handler A, Turnock BJ. Local health department effectiveness in addressing the core functions of public health: essential ingredients. J Public Health Policy 1996;17:46083.

12. Miller CA, Moore KS, Richards TB, Kotelchuck M, Kaluzny AD. Longitudinal observations on a selected group of local health departments: a preliminary report. J Public Health Policy 1993;14:34-50.

13. Turnock BJ. Accrediting public health organizations: "The ducks is on the pond!" J Public Health Manage Pract 1998;4(4):vi-vii.

14. Mays GP, Halverson PK, Miller CA. Assessing the performance of the local public health system: a survey of state health agency efforts. J Public Health Manage Pract 1998;4(4):63-78.

15. Handler A, Issel M, Turnock B. A conceptual framework to measure performance of the public health system. Am J Public Health 2001:91:1235-9.

16. Centers for Disease Control and Prevention (US). National Public Health Performance Standards Program [cited 2001 Oct 24]. Available from: URL: http://www .phppo.cdc.gov/nphpsp

17. Centers for Disease Control and Prevention (US). National Public Health Performance Standards Program. Local instrument [cited 2001 Oct 24]. Available from: URL: http://www.phppo.cdc.gov/nphpsp/ localinstrument.asp

18. James A. Harrell, Office of Disease Prevention and Health Promotion, Washington, D.C., Edward L. Baker, MD, MPH, Centers for Disease Control and Prevention, Atlanta, Georgia, and the Essential Services Work Group. The Essential Services of Public Health [cited 2000 Oct 4]. Available from: URL: http://www.phppo.cdc.gov/ nphpsp/phdpp/10es.htm

19. Zeller RA, Carmines EG. Measurement in the social sciences. Cambridge (UK): Cambridge University Press; 1980 . 